Utah State University

DigitalCommons@USU

6-16-2021

\title{
Effects of Cognitive Restructuring and Defusion for Coping with Difficult Thoughts in a Predominantly White Female College Student Sample
}

Jennifer Krafft

Utah State University, jennifer.krafft@aggiemail.usu.edu

Korena S. Klimczak

Utah State University

Michael E. Levin

Utah State University, mike.levin@usu.edu

Follow this and additional works at: https://digitalcommons.usu.edu/psych_stures

Part of the Psychology Commons

\section{Recommended Citation}

Krafft, J., Klimczak, K.S. \& Levin, M.E. Effects of Cognitive Restructuring and Defusion for Coping with Difficult Thoughts in a Predominantly White Female College Student Sample. Cogn Ther Res (2021).

https://doi.org/10.1007/s10608-021-10242-4

This Article is brought to you for free and open access by the Psychology Student Works at DigitalCommons@USU. It has been accepted for inclusion in Psychology Student Research by an authorized administrator of DigitalCommons@USU. For more information, please contact digitalcommons@usu.edu.

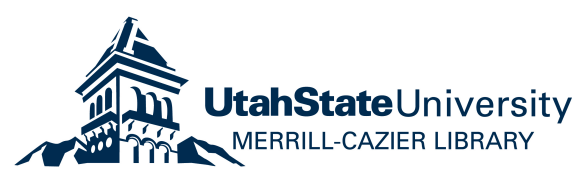


Effects of Cognitive Restructuring and Defusion for Coping with Difficult Thoughts in a Predominantly White Female College Student Sample

\author{
Jennifer Krafft $^{a}{ }^{\mathrm{a}}$, Korena S. Klimczak ${ }^{\mathrm{a}}$, and Michael E. Levin ${ }^{\mathrm{a}}$ \\ ${ }^{a}$ Utah State University, Department of Psychology, 2810 Old Main Hill, Logan, UT 84322. \\ * Corresponding author
}

Author Note

Jennifer Krafft, ORCiD: https://orcid.org/0000-0002-0943-8477

Korena S. Klimczak, ORCiD: https://orcid.org/0000-0003-2173-6431

Michael E. Levin, ORCiD: https://orcid.org/0000-0001-5562-2366

The authors declare that they have no conflict of interest. Correspondence concerning this article should be addressed to Jennifer Krafft, Department of Psychology, 2810 Old Main Hill, Logan, UT 84322-2810. Email: jennifer.krafft@aggiemail.usu.edu . 


\begin{abstract}
Background: Understanding how cognitive processes are naturally used by untrained individuals in the moment to cope with difficult thoughts may help inform effective and efficient interventions.
\end{abstract}

Methods: This study investigated self-reported naturalistic use of two evidence-based processes, cognitive restructuring and cognitive defusion, in an untrained, predominantly White female college student sample $(\mathrm{n}=194)$ through ecological momentary assessments over seven days. Results: Cognitive restructuring and defusion had a large positive relationship. Both processes were also positively associated with increased momentary use of suppression and distraction. Only momentary defusion was associated with decreased rumination and negative affect at the same timepoint, while both defusion and restructuring were associated with positive affect and increased values progress at the same timepoint. Momentary defusion predicted later values progress, but only among those with low distress.

Conclusions: Overall, results suggest that both cognitive restructuring and cognitive defusion are used in a nonclinical, untrained population, that both processes are overall beneficial when used in the moment, and that defusion may be particularly relevant to certain aims such as lower rumination or values progress across time points. Replication among clinical and more diverse populations is needed.

Keywords: ecological momentary assessment, experience sampling, cognitive restructuring, cognitive defusion, rumination 


\section{Effects of Cognitive Restructuring and Defusion for Coping with Difficult Thoughts in a Predominantly White Female College Student Sample}

Distressing and maladaptive cognitive patterns are a major feature of many psychological disorders (American Psychiatric Association, 2013) and are also common in nonclinical populations (e.g., Cash et al., 2004; Dupuy et al., 2001). Understanding and fostering cognitive processes that help individuals to effectively cope with distressing thoughts is a defining feature of cognitive behavioral therapies. Recently, there has been growing interest in a process-based therapy framework, in which identifying evidence-based processes of change, including cognitive processes, that can reliably be engaged to help alleviate human suffering is considered the core question in clinical psychology (Hofmann \& Hayes, 2018). If psychological interventions can reliably foster cognitive processes that help individuals to effectively cope with a broad range of distressing thoughts, they can alleviate suffering and support adaptive functioning.

Multiple cognitive processes have been proposed as important processes of change, including cognitive restructuring and cognitive defusion. Cognitive restructuring is defined as an active process of identifying, evaluating, and altering maladaptive thoughts such that they are more accurate or useful (Clark, 2013). Cognitive defusion is defined as a method of altering the function of thoughts, by increasing one's awareness of thoughts as thoughts rather than as representations of reality, such that thoughts have less rigid control over one's behavior (Hayes et al., 2006). There is some debate about how distinct these two processes are, but generally, cognitive restructuring focuses on altering the content of one's thoughts, while cognitive defusion focuses on altering one's relationship to thoughts (Arch \& Craske, 2008). A person who has the thought "I'm ugly" could respond in the moment by using restructuring (e.g., challenging 
whether this thought is accurate and generating alternative thoughts such as 'Actually, I like how my hair looks right now' instead), defusion (e.g., acknowledging this thought as a thought, and still choosing to wear the same outfit or do a social activity), or potentially both methods. The utility of cognitive restructuring and cognitive defusion for mental health is supported by global correlations in self-report measures (Aldao \& Nolen-Hoeksema, 2010; Krafft et al., 2019), laboratory studies (Deacon et al., 2011; Levin et al., 2012), and clinical trials (Levin, Haeger, et al., 2018; Wampold et al., 2002), and both processes have some initial support as mediators of therapeutic change (Arch et al., 2012; Smits et al., 2013; Zettle et al., 2011).

While both processes have strong research support overall, much less is known about how they are used in ecologically valid contexts (i.e., as people go about their daily lives and experience a range of challenging thoughts across different situations). Understanding the effects of these processes when spontaneously employed in real life may help to identify whether and for what purposes these processes are beneficial. Research on cognitive reappraisal in daily life suggests it may lead to greater positive affect (Brans et al., 2013; Brockman et al., 2016) and help buffer the impact of negative events (Doorley \& Kashdan, 2021); however, the effects of reappraisal are often variable depending on factors such as age (Brockman et al., 2016), level of symptoms (Farmer \& Kashdan, 2012), and type of situation (Haines et al., 2016). Moreover, studies have largely assessed the construct of cognitive reappraisal (i.e., changing thinking in order to alter mood broadly; McRae et al., 2012) rather than the more specific process of cognitive restructuring (i.e., evaluating and altering maladaptive thoughts to make them more adaptive; Clark, 2013). There is very little research on cognitive defusion in daily life, but one study found it to be related to less avoidant coping and more approach coping (Donald et al., 2017). Assessing the use of these two theoretically distinct coping strategies in combination, and 
across a range of relevant outcomes, can help clarify their utility. If individuals already use cognitive restructuring and/or cognitive defusion to help address unwanted thoughts effectively prior to intervention, therapists may be able to leverage and generalize these existing skills to foster therapeutic change. However, if individuals do not use these processes, or use them in a counterproductive way, it may be more important to teach these processes in a ground-up manner. In sum, characterizing and evaluating the naturalistic use of cognitive coping processes in the moment may help inform effective and efficient psychological interventions.

Several specific aspects of naturalistic use of cognitive processes merit investigation. First, it is unclear if cognitive defusion and restructuring are used as relatively unique strategies, or in combination with other coping strategies. In particular, individuals may use these strategies as an alternative to, or alongside, strategies that are often considered maladaptive or controloriented such as rumination, thought suppression, and distraction. In addition, cognitive coping strategies may have different effects for different outcomes; historically, the literature on cognitive restructuring has focused on altering affect, while the literature on cognitive defusion has focused on encouraging valued living (Arch \& Craske, 2008), although effects of interventions incorporating these processes are often similar (Twohig \& Levin, 2017). Examining the effects of these strategies on a range of outcomes may help to clarify whether they are distinct in terms of naturalistic effects.

Therefore, this study investigated the use of two cognitive processes, cognitive restructuring and cognitive defusion, in an unscreened, untrained population. Specifically, we sought to evaluate 1) how commonly these processes were engaged in dealing with unwanted thoughts, 2) their relationships to putatively maladaptive cognitive processes, and 3) their relationships with psychological outcomes cross-sectionally and across time points. 


\section{Participants}

\section{Methods}

This study was approved by the Institutional Review Board at the authors' institution and all participants gave their informed consent. Participants $(n=194)$ were college students who received research participation credit through undergraduate courses. Inclusion criteria were being a student at the authors' university, being 18 years of age or older, and owning an iPhone or Android; there were no additional exclusion criteria. Participants were recruited through the university's research participation platform and received up to 4 research credits, one each for completing baseline and post surveys, responding to at least $25 \%$ of EMA surveys, and responding to at least $75 \%$ of EMA surveys.

Participants were largely female (71.13\%), White $(95.88 \%)$ and young $(M=21.81$ years, $\mathrm{SD}=14.79 ;$ see Table 1 for full participant demographics). Aggregating across race and ethnicity, $91.24 \%$ of participants were non-Hispanic White. Although the sample was not screened for psychological symptoms, $46.91 \%$ exceeded the cutoff of $3+$ on the General Health Questionnaire-12 (GHQ-12) indicating a possible psychological disorder (Goldberg et al., 1997).

\section{Procedures}

All study procedures were completed online. Following an initial screening for eligibility that assessed inclusion criteria, participants provided consent through an online informed consent form, then completed a baseline survey, both hosted on the Qualtrics survey platform. At the end of this survey, they were given instructions to download and begin responding to the LifeData app, used for ecological momentary assessment (EMA) data collection. The LifeData app is a platform that allows researchers to administer repeated surveys directly to users' phones (iOS and Android) at specified intervals. The app was free for participants to download; however, researchers paid for a subscription to administer this study using the app. This app provided push 
notifications to participants' phones asking them to respond to a set of EMA questions, four times per day over seven days, between $10 \mathrm{am}$ and $10 \mathrm{pm}$. Notifications were sent randomly within 3-hour blocks within those times (10AM-1PM, 1PM-4PM, 4PM-7PM, and 7PM-10PM; and 30 minutes apart at minimum). Participants were allowed 15 minutes to respond to each notification. Prior to answering the EMA questions, participants were asked to consider any recent experiences with "challenging or negative thoughts" (full instructions are listed below). All participants were sent one reminder email encouraging continued responding two days after downloading the app; additional reminders were sent every two days if their response rate was low.

\section{EMA Measures}

\section{Positive and Negative Affect}

Participants were asked to rate 8 emotions, 4 positive (content, relaxed, enthusiastic, and joyful) and 4 negative (anxious, angry, sad and ashamed). Participants were asked to rate how much they felt each emotion "right now" from 1 (very slightly or not at all) to 5 (extremely), and positive affect (PA) and negative affect (NA) scores were calculated as the mean of the four relevant items. These items have been used in past research (Kashdan \& Farmer, 2014), with one NA item changed from sluggish to ashamed to be more relevant to this investigation on the impact of unwanted thoughts.

Momentary Values Progress

Three items asked about momentary progress toward values: "Since the last prompt...1) were you able to do what matters to you? 2) how content were you with the amount and types of things you did? 3) were your actions in line with the kind of person you want to be?" Items were rated from 1 (not at all) to 5 (very much) and a total sum score was computed. These items have 
been used in previous EMA research (Levin, Krafft, et al., 2018). Internal consistency was good for these three items $(\alpha=.85)$.

\section{Instructions}

Prior to completing the following measures of cognitive processes, participants were given these instructions: "Take a moment to think about any challenging or negative thoughts that have come up for you since the last prompt. Keep these thoughts in mind while answering the remaining questions."

\section{Restructuring}

Two novel items asked about the momentary use of cognitive restructuring: "Since the last prompt, how much did you...1) challenge the accuracy of your thoughts? 2) try to think more realistic or helpful thoughts?" Items were developed based on the Reappraisal subscale of the Thought Control Questionnaire (TCQ; Wells \& Davies, 1994). These items were rated from 1 (not at all) to 5 (very much) and averaged to generate a total momentary restructuring score. These items had adequate internal consistency $(\alpha=.71)$.

\section{Defusion}

Two items asked about momentary cognitive defusion: "Since the last prompt, how much did you...1) recognize that your thoughts are just thoughts? 2) recognize that thoughts aren't facts?" These items were newly developed by our lab with reference to two validated measures of cognitive fusion, the Cognitive Fusion Questionnaire (CFQ; Gillanders et al., 2014) and Decentering subscale of the Experiences Questionnaire (Fresco et al., 2007). These items were also rated from 1 (not at all) to 5 (very much) and averaged to generate a total momentary defusion score. Internal consistency was adequate for these items $(\alpha=.85)$.

\section{Thought Suppression, Rumination, and Distraction}


One item each asked about momentary thought suppression ("Since the last prompt, how much did you try not to think about certain things?"), rumination ("Since the last prompt, how much did you think over and over your problems?"), and distraction ("Since the last prompt, how much did you do things to distract from negative thoughts and feelings?"). These items have been used in previous EMA research (Levin, Krafft, et al., 2018). Each was rated from 1 (not at all) to 5 (very much).

\section{Analysis Plan}

Potential predictors of missing EMA surveys (age, gender, race, ethnicity, and baseline GHQ, CFQ, and TCQ-R scores) were evaluated as to whether they significantly predicted missingness in a series of binomial generalized mixed-effects models including random intercepts at the participant level. Any significant predictors identified at this stage would be included as covariates in subsequent regressions.

The construct validity of the defusion and restructuring items was assessed in terms of 1) associations with theoretically related, validated self-report measures and 2) factor loadings in an exploratory factor analysis with oblimin rotation allowing factors to correlate.

The frequency with which participants employed cognitive coping strategies was evaluated by calculating average values within each participant, then averaging across participants, based on available observations (i.e., no imputation was used).

Due to the nested nature of the data (i.e., many observations per participant), multilevel models (MLMs; also called mixed-effects models) were used to evaluate all subsequent study hypotheses. Models employed random intercepts (which model between-participant differences on the outcome) and random slopes (which model between-participant differences in slope of the outcome variable over the one-week study period). Models employed the restricted maximum 
likelihood approach to estimation. MLMs use all available information (i.e., no listwise deletion) and allow for accurate estimates of model parameters when data are missing at random (Kwok et al., 2008). MLM regression coefficients were standardized in order to provide an estimate of effect size (Lorah, 2018). All analyses were conducted with R statistical software (R Core Team, 2018). $p$-values were generated using the lmerTest package (Kuznetsova et al., 2017), which has demonstrated appropriate rates of Type I error (Luke, 2017).

First, an MLM was used to estimate the association between momentary defusion and momentary restructuring (note that the predictor and outcome are arbitrary in this model). Next, a series of six separate models estimated the associations between momentary defusion or momentary restructuring and three other cognitive processes (thought suppression, rumination, and distraction).

Subsequently, a series of three MLMs was used to evaluate whether momentary restructuring and defusion were associated with momentary NA, PA, and progress toward personal values within the same timepoint. Finally, another series of three MLMs evaluated whether momentary restructuring and defusion predicted momentary NA, PA, and progress toward personal values at the next timepoint $(t+1)$, controlling for the same outcome at the previous timepoint $(t)$.

As nearly half of the sample met the cutoff for a potential psychological disorder, exploratory analyses were conducted repeating the analyses above in two subgroups, high distress $(n=91)$ and low distress $(n=103)$ based on the GHQ-12 cutoff of 3 (Goldberg et al., 1997).

Given the potential for highly correlated predictors, the variance inflation factor (VIF) was calculated for models with multiple predictors to check for problematic multicollinearity. 
Although there is no consensus on a VIF cutoff, VIFs are considered problematic around the range of 5-10 or higher (Stine, 1995).

\section{Results}

A small number of participants $(n=6,3.09 \%)$ never downloaded the EMA app. In total, participants responded to 2868 of 5003 EMA sessions (57.33\%, an average of 14.78 responses per participant). Two participants withdrew from the study, both five days after downloading the app; however, their available data was retained for analyses. All outcome variables were inspected for skewness and kurtosis and adequately approximated normality.

In missingness analyses, demographics (age, gender, race, ethnicity) and baseline scores on key measures (GHQ, CFQ, and TCQ-R) were not significantly predictive of whether EMA surveys were completed or missing (all $p \mathrm{~s}>.05$ ). These results indicated no need to add covariates as predictors of missingness.

The defusion and restructuring EMA items were assessed for construct validity. First, two MLMs tested whether baseline scores on the CFQ and TCQ-R were associated with momentary defusion and restructuring. The momentary defusion score was significantly predicted by the TCQ-R $(\beta=0.17, p<.001)$, but not the CFQ $(\beta=-0.08, p=.06)$. The momentary restructuring score was also significantly predicted by the TCQ-R $(\beta=0.25, p<.001)$, but not the CFQ $(\beta=-0.03, p=.48)$. Given these results, the distinguishability of the EMA scales was further explored with an exploratory factor analysis using principal axis factoring and oblimin rotation of factors. This analysis was conducted on mean EMA scale scores across the timepoints for each individual. Parallel analysis indicated a two-factor solution. Results of the EFA specifying two factors indicated one factor that defusion items loaded onto (loadings of 0.87 and 1.00), but 
restructuring items did not $(0.06$ and -0.03$)$, and another factor that restructuring items loaded onto (0.79 and 0.87$)$ but defusion items did not (0.06 and -0.03$)$.

All strategies had a possible range of 1 to 5 . The average participant score for cognitive restructuring was $2.85(\mathrm{SD}=0.66)$. This indicates that on average, participants rated their recent use of cognitive restructuring approximately halfway between "not at all" and "very much," suggesting moderate use of this strategy (rather than very infrequent or very frequent use). The average participant score for cognitive defusion was $2.77(\mathrm{SD}=0.61)$. Similarly, this is approximately halfway through the possible range, suggesting moderate use of cognitive defusion on average. Average scores were 2.78 for suppression $(\mathrm{SD}=0.70), 2.93$ for distraction $(\mathrm{SD}=0.71)$, and 2.61 for rumination $(\mathrm{SD}=0.72)$. These scores similarly suggest moderate use of potentially maladaptive strategies (with slightly lower use of rumination).

In an MLM, momentary restructuring was found to be significantly associated with momentary defusion $(\beta=0.54, p<.001)$, such that a 1-SD increase in restructuring would be associated with a $0.54-\mathrm{SD}$ increase in defusion across the same time period (see Table 2). Results were very similar across the full sample and the two subgroups (high and low distress).

Momentary defusion was found to be significantly negatively associated with momentary rumination $(\beta=-0.05, p=.01)$, such that a $1-$ SD increase in defusion was associated with a 0.05 SD decrease in rumination. Momentary defusion was significantly positively associated with momentary thought suppression $(\beta=0.21, p<.001)$ and distraction $(\beta=0.23, p<.001)$, such that a 1-SD increase in defusion was associated with a $0.21-\mathrm{SD}$ increase in thought suppression and a $0.23-\mathrm{SD}$ increase in distraction. Results (in terms of direction and significance) were similar for subgroups, with the exception that defusion was not a significant predictor of 
rumination in the low-distress group $(\beta=-0.03, p>.05)$, although the regression coefficients were relatively similar across groups. Table 2 summarizes these results.

Momentary restructuring was not significantly associated with momentary rumination ( $\beta$ $=0.04, p=.06$ ), but was significantly associated with increased momentary thought suppression $(\beta=0.24, p<.001)$, and distraction $(\beta=0.24, p<.001)$. In both cases, a 1-SD increase in restructuring was associated with a $0.24-\mathrm{SD}$ increase in thought suppression and distraction. Once again results were similar across subgroups. The one difference from the results in the full sample was that momentary restructuring was associated with greater momentary rumination among those with low distress $(\beta=0.07, p=.008)$. Table 2 also summarizes these results. The models predicting suppression and distraction in the high-distress group, and rumination in the low-distress group, initially failed to converge, but converged after re-estimating without random slopes.

In the cross-sectional models, momentary defusion significantly predicted momentary NA $(\beta=-0.13, p<.001)$, while momentary restructuring did not $(\beta=0.01, p=.81)$. A $1-\mathrm{SD}$ increase in momentary defusion was associated with a $0.13-$ SD decrease in NA. Both momentary defusion $(\beta=0.15, p<.001)$ and momentary restructuring $(\beta=0.05, p=.03)$ predicted PA. This means a 1-SD increase in momentary defusion was associated with a $0.15-\mathrm{SD}$ increase in PA, and a 1-SD increase in momentary restructuring was associated with a 0.05-SD increase in PA, at the same timepoint. Both momentary defusion $(\beta=0.11, p<.001)$ and restructuring $(\beta=0.14$, $p<.001)$ were significantly associated with momentary values progress, such that a $1-\mathrm{SD}$ increase in defusion was associated with a $0.11-\mathrm{SD}$ increase in values progress, and a 1-SD increase in restructuring was associated with a $0.14-\mathrm{SD}$ increase in values progress. Results were consistent across subsamples with the one difference that restructuring did not significantly 
predict positive affect cross-sectionally for those in high distress $(\beta=0.03, p=.37)$, but coefficients were fairly similar across subgroups. See Table 3 for a summary of these models.

In the lagged models, neither momentary restructuring $(\beta=-0.01, p=.85)$ nor momentary defusion $(\beta=0.02, p=.58)$ significantly predicted later momentary NA when controlling for current NA $(\beta=0.28, p<.001)$. Similarly, neither momentary restructuring $(\beta=$ $0.03, p=.27)$ nor momentary defusion $(\beta=0.03, p=.31)$ significantly predicted momentary PA at the next timepoint when controlling for current PA $(\beta=0.26, p<.001)$. Momentary defusion $(\beta=0.05, p=.09)$ and momentary restructuring $(\beta=-0.01, p=.70)$ also did not significantly predict momentary values progress at the next timepoint when controlling for previous values progress $(\beta=0.22, p<.001)$. Results were very similar across subgroups, except that in the lowdistress group, momentary defusion predicted later values progress $(\beta=0.08, p=.04)$. Table 4 reports a summary of these models. Given the possibility that defusion and values progress were simply correlated, this analysis was reversed; however, previous values progress did not predict later defusion $(\beta=0.04, p=.21)$ controlling for defusion $(\beta=0.17, p<.001)$ and restructuring $(\beta=0.05, p=.17)$ at the same time point. VIFs did not exceed 1.55 for any model, well below the problematic range.

\section{Discussion}

This study used EMA methods to examine cognitive restructuring and cognitive defusion as they are naturally employed without any training. We employed multilevel models to evaluate whether outcomes vary between individuals based on predictors after accounting for their individual means and slopes on the outcome variable. Results indicate that both processes are used in moderate frequency, with a high correlation suggesting that they are often used over the same time periods to deal with unwanted thoughts. Both momentary restructuring and 
momentary defusion were found to be associated with potentially maladaptive cognitive strategies, specifically suppression and distraction. This may indicate that both are used as part of a broader attempt to control thoughts when these strategies are untrained. Relations with rumination were more complex, as momentary defusion was associated with lower rumination in the full sample and high-distress subsample, while momentary restructuring was associated with greater rumination in the low-distress subsample. Of note, while suppression, rumination, and distraction are often described as maladaptive, and global self-report research supports this claim (Aldao et al., 2010; Wolgast \& Lundh, 2017), the effects of any coping strategy may be contextdependent (e.g., Aldao \& Nolen-Hoeksema, 2012; Brockman et al., 2016; Kashdan \& Collins, 2010), such that no strategy is inherently adaptive or maladaptive. Further examining how context (e.g., variability in use based on situational or individual factors) influences the utility of these strategies would be highly beneficial.

Cross-sectional analyses found that momentary defusion predicted lower NA and higher PA in all groups, while momentary restructuring was unrelated to NA and associated with higher PA in the full sample and low-distress group. Both strategies were found to predict values progress. When time was accounted for through a lagged model, in general neither strategy was predictive of either PA, NA or values progress at the next time point. However, momentary defusion did predict later values progress in the low-distress group (and values progress did not predict later defusion).

These results suggest that when untrained on these strategies, individuals tend to use both momentary restructuring and momentary defusion as part of a broader set of coping strategies for unwanted thoughts, which also includes suppression and distraction. As used naturalistically, the effects of these strategies and their correlations with other coping strategies appear to be largely 
similar. For example, both are related to greater positive affect and values progress crosssectionally, and their longitudinal impact is unclear. However, there are some signs of potential differences. Momentary defusion may be linked with less rumination, while momentary restructuring may be linked with greater rumination depending on level of distress. Momentary defusion was also consistently related to less negative affect; however, the direction of this relationship is unclear and it is possible that those with less negative affect are more easily able to defuse. In addition, there was some support for the utility of defusion longitudinally in the low-distress group.

Cognitive fusion has been previously found to be a stronger predictor of mental health concerns than cognitive reappraisal (Krafft et al., 2019). If the relationship with one's thought (i.e., fusion) bears a heavier weight on mental health than cognitive content (i.e., reappraisal), it would make sense that defusion may be more advantageous in some circumstances. Some studies have found defusion to be significantly more effective for managing negative thoughts as well as for reducing acting on food cravings (Larsson et al., 2015; Moffitt et al., 2012). It should be noted that other studies have found approximately equivalent positive outcomes between the two, albeit with potential differences in underlying processes of change (Barrera et al., 2016; Deacon et al., 2011; Levin, Haeger, et al., 2018; Yovel et al., 2014). The results in the present study are broadly consistent with this literature, finding overall a similar pattern of results but with defusion potentially having broader and more long-lasting impact.

Our findings regarding the frequency and effectiveness of cognitive defusion and restructuring hold implications for treatment. As these two strategies tend to be employed with moderate frequency even without prior training, therapists can leverage these already-known skills when working with clients. For example, therapists are likely able to elicit recognition and 
use of these skills through experiential exercises with limited didactic explanation beforehand. If defusion is being introduced in the context of an acceptance-based treatment, therapists should place emphasis on defusion as an alternative to control, given that individuals may use defusion as a cognitive-control strategy when it has not yet been formally trained.

The high correlation in momentary use between these two strategies suggests that individuals may tend to utilize both with little differentiation. Thus, therapists may want to closely monitor for instances in which clients are confounding one strategy for another, and explicitly differentiate the two when introducing either strategy. Although the direction of these relationships is unclear, it is possible that cognitive defusion is a more efficient treatment target for reducing rumination and negative affect. Further research examining these relationships across different timeframes and considering potential moderating variables in the examined relationships is needed before making firm clinical recommendations. Some research has indicated that the effectiveness of each approach may depend on moderators such as presenting problem or individual characteristics (Wolitzky-Taylor et al., 2012), and the differential findings based on level of distress here also support the importance of individual context.

Notable limitations to the present study included potential sample, measurement, and statistical issues. First, this study used an undergraduate college student sample, possibly limiting the generalizability of our findings due to likely differences in education, socioeconomic status, psychological mindedness, and distress as compared to the general population or a clinical sample. Additionally, our sample was primarily young, female, and White, with this lack of diversity in sample characteristics making it unclear as to whether results can be generalized to non-traditional college students or those belonging to minority groups. 
Furthermore, while this study intentionally used an untrained sample, it is possible that the high correlation between strategies was attributable to individuals lacking clarity on which strategies they use. Indeed, it is possible that individuals used cognitive defusion as an attempt to control or eliminate thoughts, which would be inconsistent with cognitive defusion as defined theoretically (Hayes et al., 2006). Replicating this study in a treatment sample would help address whether exposure to cognitive restructuring and/or defusion (as taught in treatment) affects these findings; gathering qualitative data could also help clarify how these strategies were used. Also, novel EMA items were used in this study, and while the defusion and restructuring items were face valid and distinct in terms of factor loadings, other analyses suggested potential limits to construct validity. Items assessing rumination, distraction, and suppression had been used previously, but may not have assessed responses to the exact same content as the defusion and restructuring items, as some referred to responses to thoughts and feelings more broadly.

There was also a high nonresponse rate. As participants were prompted throughout daily life and only had a 15-minute window to respond, some missing data was unavoidable. Anecdotally, participants sometimes reported being unable to respond while in class or at work. However, it is possible that participants might have also failed to respond in a way relevant to the content of the study (i.e., when particularly stressed). Future studies would benefit from gathering data on nonresponse and potentially taking additional steps to encourage responding whenever possible such as further incentivizing responses. Of note, while this study gathered longitudinal data, most significant relationships were cross-sectional; as such, their direction cannot be determined. Finally, analyses used multiple models without adjusting p-values, inflating our family-wise error rate. However, such practices are normative and appropriate for 
exploratory research. Replication studies using clinical and diverse samples as well as items thoroughly validated for EMA contexts are needed. 


\section{References}

Aldao, A., \& Nolen-Hoeksema, S. (2010). Specificity of cognitive emotion regulation strategies: A transdiagnostic examination. Behaviour Research and Therapy, 48, 974-983. https://doi.org/10.1016/j.brat.2010.06.002

Aldao, A., \& Nolen-Hoeksema, S. (2012). The influence of context on the implementation of adaptive emotion regulation strategies. Behaviour Research and Therapy, 50, 493-501. https://doi.org/10.1016/j.brat.2012.04.004

Aldao, A., Nolen-Hoeksema, S., \& Schweizer, S. (2010). Emotion-regulation strategies across psychopathology: A meta-analytic review. Clinical Psychology Review, 30, 217-237. https://doi.org/10.1016/j.cpr.2009.11.004

American Psychiatric Association. (2013). Diagnostic and statistical manual of mental disorders (5th ed.). American Psychiatric Publishing.

Arch, J. J., \& Craske, M. G. (2008). Acceptance and commitment therapy and cognitive behavioral therapy for anxiety disorders: Different treatments, similar mechanisms? Clinical Psychology: Science and Practice, 15, 263-279.

Arch, J. J., Wolitzky-Taylor, K. B., Eifert, G. H., \& Craske, M. G. (2012). Longitudinal treatment mediation of traditional cognitive behavioral therapy and acceptance and commitment therapy for anxiety disorders. Behaviour Research and Therapy, 50, 469-478. https://doi.org/10.1016/j.brat.2012.04.007

Barrera, T. L., Szafranski, D. D., Ratcliff, C. G., Garnaat, S. L., \& Norton, P. J. (2016). An experimental comparison of techniques: Cognitive defusion, cognitive restructuring, and invivo exposure for social anxiety. Behavioural and Cognitive Psychotherapy, 44(2), 249254. https://doi.org/10.1017/S1352465814000630 
Brans, K., Koval, P., Verduyn, P., Lim, Y. L., \& Kuppens, P. (2013). The regulation of negative and positive affect in daily life. Emotion, 13, 926-939. https://doi.org/10.1037/a0032400

Brockman, R., Ciarrochi, J., Parker, P., \& Kashdan, T. (2016). Emotion regulation strategies in daily life: Mindfulness, cognitive reappraisal and emotion suppression. Cognitive Behaviour Therapy, 46, 91-113. https://doi.org/10.1080/16506073.2016.1218926

Cash, T. F., Phillips, K. A., Santos, M. T., \& Hrabosky, J. I. (2004). Measuring "negative body image": Validation of the Body Image Disturbance Questionnaire in a nonclinical population. Body Image, 1(4), 363-372. https://doi.org/10.1016/j.bodyim.2004.10.001

Clark, D. A. (2013). Cognitive restructuring. In The Wiley Handbook of Cognitive Behavioral Therapy (pp. 1-22). https://doi.org/10.1002/9781118528563.wbcbt02

Deacon, B. J., Fawzy, T. I., Lickel, J. J., \& Wolitzky-Taylor, K. B. (2011). Cognitive defusion versus cognitive restructuring in the treatment of negative self-referential thoughts: An investigation of process and outcome. Journal of Cognitive Psychotherapy, 25, 218-232. https://doi.org/10.1891/0889-8391.25.3.218

Donald, J. N., Atkins, P. W. B., Parker, P. D., Christie, A. M., \& Guo, J. (2017). Cognitive defusion predicts more approach and less avoidance coping with stress, independent of threat and self-efficacy appraisals. Journal of Personality, 85(5), 716-729. https://doi.org/10.1111/jopy.12279

Doorley, J. D., \& Kashdan, T. B. (2021). Positive and Negative Emotion Regulation in College Athletes: A Preliminary Exploration of Daily Savoring, Acceptance, and Cognitive Reappraisal. Cognitive Therapy and Research, 0123456789. https://doi.org/10.1007/s10608-020-10202-4

Dupuy, J. B., Beaudoin, S., Rhéaume, J., Ladouceur, R., \& Dugas, M. J. (2001). Worry: Daily 
self-report in clinical and non-clinical populations. Behaviour Research and Therapy, 39(10), 1249-1255. https://doi.org/10.1016/S0005-7967(01)00011-0

Farmer, A. S., \& Kashdan, T. B. (2012). Social Anxiety and Emotion Regulation in Daily Life: Spillover Effects on Positive and Negative Social Events. Cognitive Behaviour Therapy, 41(2), 152-162. https://doi.org/10.1080/16506073.2012.666561

Fresco, D. M., Moore, M. T., van Dulmen, M. H. M., Segal, Z. V., Ma, S. H., Teasdale, J. D., \& Williams, J. M. G. (2007). Initial Psychometric Properties of the Experiences Questionnaire: Validation of a Self-Report Measure of Decentering. Behavior Therapy, 38(3), 234-246. https://doi.org/10.1016/j.beth.2006.08.003

Gillanders, D. T., Bolderston, H., Bond, F. W., Dempster, M., Flaxman, P. E., Campbell, L., Kerr, S., Tansey, L., Noel, P., Ferenbach, C., Masley, S., Roach, L., Lloyd, J., May, L., Clarke, S., \& Remington, B. (2014). The development and initial validation of the Cognitive Fusion Questionnaire. Behavior Therapy, 45(1), 83-101. https://doi.org/10.1016/j.beth.2013.09.001

Goldberg, D. P., Gater, R., Sartorius, N., Ustun, T. B., Piccinelli, M., Gureje, O., \& Rutter, C. (1997). The validity of two versions of the GHQ in the WHO study of mental illness in general health care. Psychological Medicine, 27(1), 191-197. https://doi.org/10.1017/S0033291796004242

Haines, S. J., Gleeson, J., Kuppens, P., Hollenstein, T., Ciarrochi, J., Labuschagne, I., Grace, C., \& Koval, P. (2016). The wisdom to know the difference: Strategy-situation fit in emotion regulation in daily life Is associated with well-being. Psychological Science, 27(12), 16511659. https://doi.org/10.1177/0956797616669086

Hayes, S. C., Luoma, J. B., Bond, F. W., Masuda, A., \& Lillis, J. (2006). Acceptance and 
Commitment Therapy: Model, processes and outcomes. Behaviour Research and Therapy, 44, 1-25. https://doi.org/10.1016/j.brat.2005.06.006

Hofmann, S. G., \& Hayes, S. C. (2018). The future of intervention science: Process-based therapy. Clinical Psychological Science, 7, 37-50. https://doi.org/10.1177/2167702618772296

Kashdan, T. B., \& Collins, R. L. (2010). Social anxiety and the experience of positive emotion and anger in everyday life: an ecological momentary assessment approach. Anxiety, Stress \& Coping, 23(3), 259-272. https://doi.org/10.1080/10615800802641950

Kashdan, T. B., \& Farmer, A. S. (2014). Differentiating emotions across contexts: Comparing adults with and without social anxiety disorder using random, social interaction, and daily experience sampling. Emotion, 14(3), 629-638. https://doi.org/10.1037/a0035796

Krafft, J., Haeger, J. A., \& Levin, M. E. (2019). Comparing cognitive fusion and cognitive reappraisal as predictors of college student mental health. Cognitive Behaviour Therapy, 48(3). https://doi.org/10.1080/16506073.2018.1513556

Kuznetsova, A., Brockhoff, P. B., \& Christensen, R. H. B. (2017). lmerTest package: tests in linear mixed effects models. Journal of Statistical Software, 82.

Kwok, O. M., Underhill, A. T., Berry, J. W., Luo, W., Elliott, T. R., \& Yoon, M. (2008). Analyzing longitudinal data with multilevel models: An example with individuals living with lower extremity intra-articular fractures. Rehabilitation Psychology, 53(3), 370-386. https://doi.org/10.1037/a0012765

Larsson, A., Hooper, N., Osborne, L. A., Bennett, P., \& McHugh, L. (2015). Using brief cognitive restructuring and cognitive defusion techniques to cope with negative thoughts. Behavior Modification, 40(3), 452-482. https://doi.org/10.1177/0145445515621488 
Levin, M. E., Haeger, J., An, W., \& Twohig, M. P. (2018). Comparing cognitive defusion and cognitive restructuring delivered through a mobile app for individuals high in self-criticism. Cognitive Therapy and Research, 42(6), 844-855. https://doi.org/10.1007/s10608-0189944-3

Levin, M. E., Hildebrandt, M. J., Lillis, J., \& Hayes, S. C. (2012). The impact of treatment components suggested by the psychological flexibility model: A meta-analysis of laboratory-based component studies. Behavior Therapy, 43(4), 741-756. https://doi.org/10.1016/j.beth.2012.05.003

Levin, M. E., Krafft, J., Pierce, B., \& Potts, S. (2018). When is experiential avoidance harmful in the moment? Examining global experiential avoidance as a moderator. Journal of Behavior Therapy and Experimental Psychiatry, 61, 158-163. https://doi.org/10.1016/j.jbtep.2018.07.005

Lorah, J. (2018). Effect size measures for multilevel models: definition, interpretation, and TIMSS example. Large-Scale Assessments in Education, 6. https://doi.org/10.1186/s40536018-0061-2

Luke, S. G. (2017). Evaluating significance in linear mixed-effects models in R. Behavior Research Methods, 49, 1494-1502. https://doi.org/10.3758/s13428-016-0809-y

McRae, K., Ciesielski, B., \& Gross, J. J. (2012). Unpacking cognitive reappraisal: goals, tactics, and outcomes. Emotion (Washington, D.C.), 12(2), 250-255. https://doi.org/10.1037/a0026351

Moffitt, R., Brinkworth, G., Noakes, M., \& Mohr, P. (2012). A comparison of cognitive restructuring and cognitive defusion as strategies for resisting a craved food. Psychology \& Health, 27(sup2), 74-90. https://doi.org/10.1080/08870446.2012.694436 
R Core Team. (2018). R: A language and environment for statistical computing. R Foundation for Statistical Computing.

Smits, J. A. J., Julian, K., Rosenfield, D., \& Powers, M. B. (2013). Threat reappraial as a mediator of symptom change in cognitive-behavioral treatment of anxiety disorders: A systematic review. Journal of Consulting and Clinical Psychology, 80(4), 624-635. https://doi.org/10.1037/a0028957.Threat

Stine, R. A. (1995). Graphical interpretation of variance inflation factors. The American Statistician, 49(1), 53-56.

Twohig, M. P., \& Levin, M. E. (2017). Acceptance and commitment therapy as a treatment for anxiety and depression: A review. Psychiatric Clinics, 40(4), 751-770.

Wampold, B. E., Minami, T., Baskin, T. W., \& Tierney, S. C. (2002). A meta-(re)analysis of the effects of cognitive therapy versus 'other therapies' for depression. Journal of Affective Disorders, 68, 159-165. www.elsevier.com/locate/jad

Wells, A., \& Davies, M. I. (1994). The thought control questionnaire: A measure of individual differences in the control of unwanted thoughts. Behaviour Research and Therapy, 32(8), 871-878. https://doi.org/10.1016/0005-7967(94)90168-6

Wolgast, M., \& Lundh, L. G. (2017). Is distraction an adaptive or maladaptive strategy for emotion regulation? A person-oriented approach. Journal of Psychopathology and Behavioral Assessment, 39(1), 117-127. https://doi.org/10.1007/s10862-016-9570-x

Wolitzky-Taylor, K. B., Arch, J. J., Rosenfield, D., \& Craske, M. G. (2012). Moderators and non-specific predictors of treatment outcome for anxiety disorders: A comparison of cognitive behavioral therapy to acceptance and commitment therapy. Journal of Consulting and Clinical Psychology, 80, 786-799. https://doi.org/10.1037/a0029418 
Yovel, I., Mor, N., \& Shakarov, H. (2014). Examination of the core cognitive components of cognitive behavioral therapy and acceptance and commitment therapy: An analogue investigation. Behavior Therapy, 45(4), 482-494.

https://doi.org/10.1016/j.beth.2014.02.007

Zettle, R. D., Rains, J. C., \& Hayes, S. C. (2011). Processes of change in acceptance and commitment therapy and cognitive therapy for depression: a mediation reanalysis of Zettle and Rains. Behavior Modification, 35(3), 265-283.

https://doi.org/10.1177/0145445511398344 
Table 1. Participant demographics

\begin{tabular}{|c|c|}
\hline & Mean/Count (SD/\%) \\
\hline & $\mathrm{n}=194$ \\
\hline \multicolumn{2}{|l|}{ Age } \\
\hline & $21.81(14.79)$ \\
\hline \multicolumn{2}{|l|}{ Gender } \\
\hline Male & $56(28.87 \%)$ \\
\hline Female & $138(71.13 \%)$ \\
\hline \multicolumn{2}{|l|}{ Ethnicity } \\
\hline Hispanic & $9(4.64 \%)$ \\
\hline Not Hispanic & $185(95.36 \%)$ \\
\hline \multicolumn{2}{|l|}{ Race } \\
\hline American Indian/Alaska Native & $1(0.52 \%)$ \\
\hline Asian & $3(1.55 \%)$ \\
\hline Black & $2(1.03 \%)$ \\
\hline White & $186(95.88 \%)$ \\
\hline Bi/Multi-racial & $2(1.03 \%)$ \\
\hline American Indian/Alaska Native & $1(0.52 \%)$ \\
\hline \multicolumn{2}{|l|}{ Income } \\
\hline Less than $20 \mathrm{k}$ & $47(24.23 \%)$ \\
\hline $20-40 \mathrm{k}$ & $22(11.34 \%)$ \\
\hline $40-60 \mathrm{k}$ & $14(7.22 \%)$ \\
\hline $60-80 \mathrm{k}$ & $23(11.86 \%)$ \\
\hline $80-100 \mathrm{k}$ & $14(7.22 \%)$ \\
\hline More than $100 \mathrm{k}$ & $31(15.98 \%)$ \\
\hline Unknown & $43(22.16 \%)$ \\
\hline \multicolumn{2}{|l|}{ Wellbeing (GHQ) } \\
\hline & $3.61(3.48)$ \\
\hline
\end{tabular}


Table 2. MLMs evaluating associations between processes

\begin{tabular}{|c|c|c|c|c|c|c|}
\hline & \multicolumn{2}{|c|}{ Full Sample $(n=194)$} & \multicolumn{2}{|c|}{ High Distress $(n=91)$} & \multicolumn{2}{|c|}{ Low Distress $(n=103)$} \\
\hline & $\underline{\text { Restructuring } \beta}$ & $\underline{\text { Defusion } \beta}$ & $\underline{\text { Restructuring } \beta}$ & $\underline{\text { Defusion } \beta}$ & $\underline{\text { Restructuring } \beta}$ & $\underline{\text { Defusion } \beta}$ \\
\hline \multicolumn{7}{|l|}{ Process } \\
\hline Defusion & $0.54 * * *$ & & $0.57 * * *$ & & $0.52 * * *$ & \\
\hline Rumination & 0.04 & $-0.05^{*}$ & 0.00 & $-0.07 *$ & $0.07 * *$ & -0.03 \\
\hline $\begin{array}{l}\text { Thought } \\
\text { suppression }\end{array}$ & $0.24 * * *$ & $0.21 * * *$ & $0.24 * * *$ & $0.15 * * *$ & $0.25 * * *$ & $0.26 * * *$ \\
\hline Distraction & $0.24 * * *$ & $0.23 * * *$ & $0.26 * * *$ & $0.20 * * *$ & $0.23 * * *$ & $0.25 * * *$ \\
\hline
\end{tabular}

Note. ${ }^{* * *} p<.001, * * p<.01,{ }^{*} p<.05$. High-distress group refers to those scoring a 3 or higher on the GHQ-12, while low-distress group refers to those scoring a 2 or lower (Goldberg et al., 1997). 
Table 3. MLMs evaluating cross-sectional associations between cognitive processes and outcomes

\begin{tabular}{|c|c|c|}
\hline & \multicolumn{2}{|c|}{ Full Sample $(n=194)$} \\
\hline & $\underline{\text { Restructuring } \beta}$ & $\underline{\text { Defusion } \beta}$ \\
\hline \multicolumn{3}{|l|}{ Outcome } \\
\hline NA & 0.01 & $-0.13 * * *$ \\
\hline PA & $0.05^{*}$ & $0.15 * * *$ \\
\hline \multirow[t]{3}{*}{ Values progress } & $0.14 * * *$ & $0.11 * * *$ \\
\hline & \multicolumn{2}{|c|}{ High Distress $(\mathrm{n}=91)$} \\
\hline & $\underline{\text { Restructuring } \beta}$ & Defusion $\beta$ \\
\hline \multicolumn{3}{|l|}{ Outcome } \\
\hline NA & 0.00 & $-0.14 * * *$ \\
\hline PA & 0.03 & $0.18 * * *$ \\
\hline \multirow[t]{3}{*}{ Values progress } & $0.14 * * *$ & $0.14 * * *$ \\
\hline & \multicolumn{2}{|c|}{ Low Distress $(\mathrm{n}=103)$} \\
\hline & $\underline{\text { Restructuring } \beta}$ & $\underline{\text { Defusion } \beta}$ \\
\hline \multicolumn{3}{|l|}{ Outcome } \\
\hline NA & 0.01 & $-0.12 * *$ \\
\hline PA & $0.06^{*}$ & $0.12 * * *$ \\
\hline Values progress & $0.13 * * *$ & $0.08 * *$ \\
\hline
\end{tabular}

Note. $* * * p<.001, * * p<.01, * p<.05$. 
Table 4. MLMs evaluating lagged associations between cognitive processes and outcomes controlling for outcome at previous time point

\begin{tabular}{|c|c|c|c|}
\hline & \multicolumn{3}{|c|}{ Full Sample $(\mathrm{n}=194)$} \\
\hline & $\underline{\text { Previous }}$ & Restructuring $\beta$ & Defusion $\beta$ \\
\hline & NA/PA/Values & & \\
\hline & $\overline{\operatorname{progress} \beta}$ & & \\
\hline \multicolumn{4}{|l|}{ Outcome } \\
\hline Lagged NA & $0.28 * * *$ & -0.01 & 0.02 \\
\hline Lagged PA & $0.26 * * *$ & 0.03 & 0.03 \\
\hline \multirow{5}{*}{$\begin{array}{l}\text { Lagged values } \\
\text { progress }\end{array}$} & $0.22 * * *$ & -0.01 & 0.05 \\
\hline & \multicolumn{3}{|c|}{ High Distress $(n=91)$} \\
\hline & $\underline{\text { Previous }}$ & $\underline{\text { Restructuring } \beta}$ & $\underline{\text { Defusion } \beta}$ \\
\hline & $\underline{\text { NA/PA/Values }}$ & & \\
\hline & progress $\beta$ & & \\
\hline \multicolumn{4}{|l|}{ Outcome } \\
\hline Lagged NA & $0.32 * * *$ & 0.00 & 0.05 \\
\hline Lagged PA & $0.25 * * *$ & 0.04 & 0.00 \\
\hline \multirow{5}{*}{$\begin{array}{l}\text { Lagged values } \\
\text { progress }\end{array}$} & $0.24 * * *$ & -0.01 & 0.02 \\
\hline & \multicolumn{3}{|c|}{ Low Distress $(\mathrm{n}=103)$} \\
\hline & $\underline{\text { Previous }}$ & $\underline{\text { Restructuring } \beta}$ & Defusion $\beta$ \\
\hline & $\underline{\text { NA/PA/Values }}$ & & \\
\hline & progress $\beta$ & & \\
\hline Outcome & & & \\
\hline Lagged NA & $0.24 * * *$ & -0.01 & 0.00 \\
\hline Lagged PA & $0.25 * * *$ & 0.02 & 0.05 \\
\hline $\begin{array}{l}\text { Lagged values } \\
\text { progress }\end{array}$ & 0.13 & -0.03 & $0.08 *$ \\
\hline
\end{tabular}

